\title{
Proteinases as virulence factors in Leishmania spp. infection in mammals
}

\author{
Mariana Silva-Almeida, Bernardo Acácio Santini Pereira, Michelle Lopes Ribeiro-Guimarães \\ and Carlos Roberto Alves ${ }^{*}$
}

\begin{abstract}
Leishmania parasites cause human tegumentary and visceral infections that are commonly referred to as leishmaniasis. Despite the high incidence and prevalence of cases, leishmaniasis has been a neglected disease because it mainly affects developing countries. The data obtained from the analysis of patients' biological samples and from assays with animal models confirm the involvement of an array of the parasite's components in its survival inside the mammalian host. These components are classified as virulence factors. In this review, we focus on studies that have explored the role of proteinases as virulence factors that promote parasite survival and immune modulation in the mammalian host. Additionally, the direct involvement of proteinases from the host in lesion evolution is analyzed. The gathered data shows that both parasite and host proteinases are involved in the clinical manifestation of leishmaniasis. It is interesting to note that although the majority of the classes of proteinases are present in Leishmania spp., only cysteine-proteinases, metalloproteinases and, to a lesser scale, serine-proteinases have been adequately studied. Members from these classes have been implicated in tissue invasion, survival in macrophages and immune modulation by parasites. This review reinforces the importance of the parasite proteinases, which are interesting candidates for new chemo or immunotherapies, in the clinical manifestations of leishmaniasis.
\end{abstract}

Keywords: Leishmania spp., Leishmaniasis, Protease, Proteinase, Lesion

\section{Review Introduction}

Leishmaniasis is a vector-borne infection that is present in the Americas, Africa, eastern Europe, western and central Asia, India and Australia [1,2]. The genus Leishmania includes protozoan parasites that cause several types of human infections ranging from the visceral form to the tegumentary forms (cutaneous, diffuse cutaneous, mucocutaneous and post-kalazar dermal). In addition to humans, animals such as dogs, rodents and marsupials are also susceptible to Leishmania infections [3].

Currently, it is estimated that 1-1.5 million new cases of tegumentary leishmaniasis and 0.5 million new cases of the visceral form occur each year [4], and the number of leishmaniasis cases occurring outside of the endemic

\footnotetext{
* Correspondence: calves@ioc.fiocruz.br

Laboratório de Biologia Molecular e Doenças Endêmicas, IOC, Fiocruz,

Avenida Brasil, 4365 Manguinhos Pavilhão Leônidas Deane - sala 209, CEP: 21040-900, Rio de Janeiro, RJ, Brasil
}

countries has been increasing due to tourism, military operations and the movement of immigrants from endemic countries [5]. There are two evident morphological phases in the life cycle of these protozoa: (1) elongated promastigotes with visible flagella that inhabit sandfly guts and (2) round-shaped amastigotes without visible flagella that inhabit mammalian cells [6]. During the natural infection, the metacyclic promastigotes are carried by the blood-sucking sandflies that mediate the transmission between mammalian hosts. It has been reported that, in some human cases, the hosts may remain asymptomatic for a long time and thus play an important role in the vector-borne transmission of leishmaniasis in their regions [7].

During the blood meal, the insect vector deposits metacyclic promastigotes in the skin of its host. These promastigotes are the virulent form of Leishmania and initiate the infection. The first sign of infection is a small erythema at the site of the sandfly bite that develops after a variable incubation period. The erythema 
progresses into a papule and then into a nodule that gradually ulcerates over a period ranging from two weeks to six months, eventually becoming the characteristic lesion of localized cutaneous leishmaniasis, as reviewed by [8]. Once in the skin, the parasites are exposed to new microenvironments, such as the extracellular matrix (ECM) of connective tissue, and must interact with a variety of obstacles, including basement membrane proteins, until establishing infection within macrophage phagolysosomes $[9,10]$.

Currently, it is known that the distinct clinical manifestations of leishmaniasis are dependent upon the parasite species and the status of the host's immune system [10] and result from interactions between host immune factors and parasite components. These manifestations can be divided into three main profiles: (1) an anergic pole, where ulceration is not observed even with a high parasite number in the lesion, characterizes the diffuse cutaneous form; (2) an equilibrated profile characterizes the localized cutaneous form or benign disease, and (3) a hypergenic pole that is observed in mucosal leishmaniasis, in which few parasites are found in the lesions despite the elevated cellular response of the host [11-14].

Some parasite components are characterized as virulence factors that contribute to Leishmania pathogenesis and enable the parasite to invade and establish infection in the mammalian host [15]; these virulence factors include glicoinositolphospholipids (GIPLs), lipophosphoglycan (LPG), proteophosphoglycan (PPG) and the $11 \mathrm{kDa}$ kinetoplastid membrane protein (KMP-11). Although the exact impact of these Leishmania components on the clinical manifestations observed in mammalian hosts is not yet defined, there is evidence that these components modulate the interactions between Leishmania and host immune cells.

For example, GIPLs were reported to help Leishmania (Leishmania) major survive inside macrophages by inhibiting nitric oxide synthase [16] and protein kinase $C$ [17]. Recently, a correlation was shown between the rate of macrophage infection by Leishmania (Viannia) braziliensis and the GILP-containing detergent-resistant membrane domains of this parasite [18].

Lipophosphoglycan is a macrophage ligand that is directly involved in the initial stages of the infection. Assays carried out with a mutant strain of $L$. (L.) major deficient in the gene $\operatorname{lpg} 1\left(\operatorname{lpg} 1^{-}\right)$showed that the mutant parasites are attenuated for virulence during infections of murine macrophages, despite presenting no major phenotypical changes. These parasites lacked LPG but contained normal levels of related glycoconjugates and GPI-anchored proteins. The $\operatorname{lpg} 1^{-}$promastigotes are highly susceptible to the complement system and to the oxidants produced by host cells. In addition, they lose their ability to inhibit phagolysosome fusion. It has also been reported that $L$. (L.) major LPG2 null mutants $\left(\operatorname{lpg} 2^{-}\right)$were unable to survive in sandflies or in mammalian host cells. These parasites were more altered than the lpg1- mutants and lacked all phosphoglycans, including LPG and proteophosphoglycans [19-23]. Leishmania LPG has been shown to impair the nuclear translocation of NF- $\mathrm{kB}$ in monocytes, leading to a subsequent decrease in IL-12 production [24], and can also influence the host's early immune responses by modulating dendritic cells by inhibiting antigen presentation and promoting an early IL-4 response [25].

Proteophosphoglycans are highly glycosylated polypeptides with O-glycosylations similar to those found in the LPG and acid phosphatase [26,27]. The function of membrane PPGs is not entirely clear, but it is speculated that its long chain that covers the plasma membrane of the parasite could play some role in binding to macrophage receptors. The secretion of modified PPG by parasites within macrophages appears to contribute to maintenance of the parasitophorous vacuole [28]. Additionally, the PPG is also able to activate complement via mannose-binding protein [29].

KMP-11 is a hydrophobic protein that has been described to be associated to LPG [30]. This protein has presented immunoregulatory properties and is able to induce the expression of IL-10 in cells from patients with cutaneous and mucocutaneous leishmaniasis [31]; however, the mechanism through which this effect occurs remains unclear.

\section{Proteinases of Leishmania as virulence factors}

Proteinases are also important virulence factor candidates, as they are enzymes that hydrolyze peptide bonds and thus have the potential to degrade proteins and peptides that participate in a broad range of biological functions, including the infection process (Table 1). Proteinases occur ubiquitously in biological systems and have functions that range from the digestion of proteins for nutritive purposes to the exquisite control of protein function by hydrolyzing a highly specific peptide bond in a protein substrate [32].

They can be classified, based on their catalytic domains, as serine-, threonine-, aspartyl-, metallo- and cysteine-proteinases [63]. Among these, only the aspartyl-, metallo- and cysteine-proteinase classes have been extensively studied in Leishmania species [64-67].

There are several examples of parasite proteinases being involved in pathogenesis and playing roles in parasite invasion and migration through host tissues, degradation of immune related proteins, immune evasion and activation of inflammation [68]. In protozoan parasites, proteinases play key roles in the life cycle transitions, invasion of hosts, migration through tissue barriers, degradation of hemoglobin and other blood proteins, 
Table 1 Immunological actions of proteinases on the mammalian immune system that drive clinical manifestations of Leishmaniases

\begin{tabular}{|c|c|c|c|c|}
\hline Proteinase classes & & Leishmania species & Activities on mammalian host & References \\
\hline \multirow[t]{12}{*}{ Cysteine proteinase } & CPA & L. (L.) infantum & Related to the ability to infect mammalian hosts cells in vitro; & [33] \\
\hline & \multirow[t]{9}{*}{ CPB } & \multirow[t]{2}{*}{ L. (L.) mexicana } & $\begin{array}{l}\text { Associated with a Th2 profile in BALB/c mice: inducing lesions; IL-4 and IL-5 } \\
\text { production; inhibition of IL-12 production by cleaving NF-KB; inhibition of NO } \\
\text { production by cleaving the STAT-1 and AP-1 transcription factors. }\end{array}$ & \multirow[t]{2}{*}{ [34-42] } \\
\hline & & & $\begin{array}{l}\text { Associated with a Th1 profile in C3HeB/FeJ and C57BL/6 mice: expression of } \\
\text { Th1-associated cytokines; }\end{array}$ & \\
\hline & & \multirow[t]{3}{*}{ L. (L.) amazonensis } & Associated with the cleavage of MHC class II gene products in mice; & \multirow[t]{3}{*}[43-46]{} \\
\hline & & & $\begin{array}{l}\text { Epitopes from CPB COOH-terminal extension modulate infection in BALB/C and } \\
\text { CBA mice: induce Th1 or Th2-related cytokines; stimulate CD8+ T lymphocytes; }\end{array}$ & \\
\hline & & & Endogenous CP inhibitors are related with immune modulation & \\
\hline & & L. (L.) major & Associated with a Th1 profile and reduction of IFN- $\gamma$ expression in $\mathrm{C} 3 \mathrm{HeB} / \mathrm{FeJ}$ mice; & [37] \\
\hline & & L. (L.) pifanoi & $\begin{array}{l}\text { Reduces the percentage of infected murine macrophages when parasites are } \\
\text { treated with an anti-C-terminal extension antibody }\end{array}$ & [47] \\
\hline & & \multirow[t]{2}{*}{ L. (L.) chagasi } & $\begin{array}{l}\text { Associated with Th1 profile in asymptomatic patients and IFN-ץ production in cell } \\
\text { cultures; }\end{array}$ & \multirow[t]{2}{*}[48]{} \\
\hline & & & $\begin{array}{l}\text { Related to Th1 and Th2 profiles in cells from symptomatic human patients and } \\
\text { dogs: IFN- }- \text {, IL-4 and IL-10 production in cell cultures; }\end{array}$ & \\
\hline & \multirow[t]{2}{*}{ CPC } & L. (L.) mexicana & Contributes to resisting killing by macrophages & [49-51] \\
\hline & & L. (L.) Chagasi & Induces TGF- $\beta$ expression in human cell culture & [52] \\
\hline \multirow[t]{3}{*}{ Metallo-proteinases } & \multirow[t]{3}{*}{ M8 } & Leishmania spp. & $\begin{array}{l}\text { Related to the hydrolysis and inactivation of immunoglobulin G; Inactivation of C3b } \\
\text { factor to complement C3bi; Adhesion and internalization in macrophages; } \\
\text { downregulation of gp63 expression induces Th1 profile in mice; cleave NF-KB } \\
\text { and prevent expression of IL-12 and iNOS in mice }\end{array}$ & {$[53-56]$} \\
\hline & & L. (L.) major & $\begin{array}{l}\text { Associated with human NK cells proliferation and cleavage CD4 glycoprotein on } \\
\text { human T cells in culture. }\end{array}$ & {$[57,58]$} \\
\hline & & L. (L.) mexicana & $\begin{array}{l}\text { In murine bone marrow macrophages, interferes with signaling cascades and affects } \\
\text { transcription factors by cleaving c-Jun, the central component of AP-1, alters signaling } \\
\text { through cleavage-activated protein tyrosine phosphatases in murine macrophages }\end{array}$ & [59] \\
\hline \multirow[t]{2}{*}{ Serine proteinases } & \multirow[t]{2}{*}{ OPB } & L. (L.) donovani & Allows parasites to infect the murine macrophage & {$[60,61]$} \\
\hline & & L. (L.) major & Related to maintenance of murine macrophage infection & {$[62]$} \\
\hline
\end{tabular}

immune evasion, and activation of inflammation in the mammalian host $[67,68]$.

A comparative genomic analysis carried out with the different species of the genus Leishmania that have been sequenced revealed that the number of proteinase genes is kept constant among the various species. However, there is a high diversity of proteinases in Leishmania, as a survey of multiple databanks reveals that $L$. (V.) braziliensis alone has at least forty-four cysteine proteinases, twenty-three serine proteinases and ninety-seven metalloproteinase (http://tritrypdb.org, http://blast.ncbi.nlm. nih.gov/). Therefore, due to the broad spectrum of action of Leishmania proteinases while the parasite is inside the mammalian host, it is reasonable to propose a correlation between proteinase activity and the clinical manifestation of leishmaniasis.

Cysteine-proteinases from Leishmania as virulence factors Many studies have identified cysteine proteinases (CPs) as prevalent virulence factors in species that are classified under the Leishmania (Leishmania) mexicana complex, especially in the murine infection model used for most of the CP studies. The efficacy of the use of CP inhibitors for infection control can be interpreted as evidence of the importance of these enzymes during the establishment of the infection in the host [69].

Cysteine proteases are enzymes that are known to play critical roles in the pathogenesis of other parasitic protozoa infections, as reviewed by [70], thus their importance as virulence factors and their potential as drug targets and vaccine candidates has been investigated extensively. The most studied CPs in Leishmania are designated $\mathrm{CPA}, \mathrm{CPB}$ and $\mathrm{CPC}$, all of which are papainlike and belong to the same group of CPs, clan CA, that is divided into families, as follows: family $\mathrm{C}$, including cathepsin B-like (e.g., CPC) and cathepsin L-like (e.g., $\mathrm{CPA}$ and $\mathrm{CPB}$ ) enzymes; family $\mathrm{C} 2$, including calpainlike enzymes; and others [34,67,69-72].

Several CP genes have been characterized in Leishmania, mainly in species of the $L$. (L.) mexicana complex, such as L. (L.) mexicana [73-75], Leishmania (Leishmania) pifanoi $[47,76]$ and Leishmania (Leishmania) amazonensis 
[77]. The genomic organization and characterization of the cathepsin L-like cysteine proteinases gene cluster from the Leishmania (Leishmania) donovani complex has been previously described [79]. It has also been observed that single nucleotide polymorphisms (SNPs) occurring in CPs, which can vary according to the parasite's life stage, could be related to clinical characteristics such as a dermotropic rather than a viscerotropic status [79].

Additionally, a high CP activity was observed in extracts of $L$. (L.) amazonensis amastigotes, but promastigotes from the exponential or stationary phases exhibited very low proteolytic activity [77]. In this species of Leishmania, a correlation between the levels of CP expression and virulence has been described [80]. In this context, suppression of the $\mathrm{CP}$ genes diminished the virulence of Leishmania (Leishmania) infantum in hamsters [81] and of Leishmania (Leishmania) chagasi in human cell cultures [82].

CPs were also shown to play a key role in basic functions and the interactions of Leishmania (Leishmania) tropica with the host, as parasites treated with CP inhibitors showed reduced viability, growth and pathogenicity [83]. In contrast, CPA was shown to be important in the host-parasite interaction of $L$. (L.) infantum but not to be essential for parasite replication [33].

\section{CPB as a major virulence factor in species of the $L$. (L.) mexicana complex}

Proof of the importance of CPBs as a major virulence factor for species of the $L$. (L.) mexicana complex was obtained in assays of experimental infections in BALB/C mice using genetically modified parasites in which the genes for CPA, CPB and CPC were deleted $(\Delta c p a, \Delta c p b$ and $\Delta c p c$ strains). These assays showed that the absence of CPA or CPC affected the parasites in a more discrete fashion than the absence of $\mathrm{CPB}$; parasites lacking $\mathrm{CPB}$ had a greatly reduced ability to infect and induced fewer lesions than the wild-type strain [34,35].

Other studies analyzed the effects of the reinsertion of $c p b$ genes in the $\Delta c p b$ parasite strain; the reinsertion of a single $c p b$ gene did not fully restore parasite virulence, but the reinsertion of multiple $c p b$ genes (using a cosmid) was able to do so. These data suggest that the multiple copies of $c p b$ genes present in the parasites genome produce enzymes with complementary functions [36]. The role of $\mathrm{CPB}$ in the progression of infection in distinct murine strains was variable. $L$. (L.) mexicana remained able to continuously induce lesions in BALB/ c mice even after the depletion of the $c p b$ genes, although it did so at a much lower rate than wild strain parasites, indicating that other virulence factors were still effective. However, in the murine strains $\mathrm{C} 3 \mathrm{HeB} /$ FeJ and $\mathrm{C} 57 \mathrm{BL} / 6$, the infection with mutant parasites was eventually controlled and the lesions were able to heal [35-37].

Regarding the direct effect of $\mathrm{CPB}$ on the parasite's ability to control host responses, it was observed that $\Delta c p b$ L. (L.) mexicana parasites are unable to promote IL-4 expression during an experimental infection of $\mathrm{BALB} / \mathrm{c}$ mice. The infected mice were thus able to mount a Th1 response and limit lesion growth. After multiple $c p b$ genes were reinserted into the mutant parasites, the capacity to induce IL-4 production was restored along with virulence [36].

It interesting to note that the subversion of immune responses by a specific parasite species may present in different manners depending on the mouse strain used. For example, it has been reported that the virulence of L. (L.) mexicana in the mouse strains $\mathrm{C} 3 \mathrm{HeB} / \mathrm{FeJ}$ and $\mathrm{C} 57 \mathrm{BL} / 6$ is not associated with the capacity to induce IL-4 expression, as in BALB/c mice but is instead due to the inhibition of the expression of Th1-associated cytokines. Studies have shown that animals from these more resistant strains were able to control lesion growth after experimental infection with $\Delta c p b$ parasites but were susceptible to wild strain parasites. In contrast, animals became susceptible to infection by $\Delta c p b$ parasites if the IL12p40 or STAT4 genes were suppressed, suggesting that wild-type parasites inhibit the expression of Th1related genes [37].

Additionally, experiments using cosmids to insert multiple $L$. (L.) mexicana $c p b$ genes into $L$. (L.) major parasites have yielded similar results. After transfection with the $c p b$-containing cosmids, L. (L.) major parasites caused infections with higher parasitic loads and reduced IFN- $\gamma$ expression in $\mathrm{C} 3 \mathrm{HeB} / \mathrm{FeJ}$ mice than was observed for infections with the wild-type $L$. (L.) major, providing more evidence of the influence of $\mathrm{CPB}$ on the expression of Th1-related genes [37].

The role of CPB from $L$. (L.) mexicana in the inhibition of host IL-12 production was also analyzed in macrophages and dendritic cells [38,39]. The role of $\mathrm{CPB}$ in IL-12 inhibition was shown using assays with $\Delta c p b$ amastigotes that were less efficient at inhibiting the lipopolysaccharide-related expression of IL-12 than wild-type amastigotes. Supplementary evidence was obtained from the observation that the use of CPB inhibitors in wild-type parasites was similarly able to hinder the ability of amastigotes to inhibit host IL-12 expression [40]. The same study proposed a mechanism through which $\mathrm{CPB}$ could inhibit IL-12 expression: the enzyme could be involved in the cleavage of nuclear factor kappa $B(N F-\kappa B)$ and its inhibitors (I $B \alpha$ and $\beta$ ), thus preventing the expression of interleukins by the host. This IL-12 inhibition could not be observed in assays using $\Delta c p b$ amastigotes or promastigotes, because unlike amastigotes, promastigotes only express low levels of CPB [40]. 
The influence of CPB from $L$. (L.) mexicana on the activity of other transcriptional factors was further analyzed in another study that showed that this proteinase affects other transcription factors, such as STAT-1 and $\mathrm{AP}-1$, as well as NF- $\mathrm{B}$, by impeding their translocation to the nucleus and thus impairing the production of $\mathrm{NO}$ that is induced by IFN- $\gamma$ [41]. Differences in the way that promastigotes and amastigotes modulate NF- $\mathrm{kB}$ activity were also observed: while the former cleaves the p65 subunit to a smaller p35 subunit, the latter completely degrades the p65 subunit.

Another effect of $\mathrm{CPB}$ on the balance of Th responses occurs through the cleavage of MHC proteins. There is evidence that $L$. (L.) amazonensis $\mathrm{CPB}$ is able to cleave $\mathrm{MHC}$ class II proteins inside the parasitophorous vacuole of colonized host cells. Consequently, the host immune response could be partially inhibited or, alternatively, be mediated by other immune components such as the MHC class I gene products [43].

The effects of $\mathrm{CPB}$ on the murine host immune system has also been tested by subcutaneously injecting an enzymatically active recombinant $\mathrm{CPB}$ protein into the hind paw of BALB/c mice. Even without any actual parasites infecting the mice, there was an increase in IL-4 and IL-5 expression (Th2-related cytokines) and in the levels of circulating IgE. These effects may be partially explained by the ability of $\mathrm{CPB}$ to cleave CD23 (low affinity IgE receptor) and CD25 (IL-2 receptor), as a similar assay using an inactive recombinant $\mathrm{CPB}$ had no such effects on the murine hosts [42].

\section{Importance of CPB as a virulence factor in species from other complexes}

In spite of the substantial advances in knowledge about CPs from the $L$. (L.) mexicana complex and, to a lesser degree, of the $L$. (L.) donovani complex, less is known about CPs from $L$. $(V$.) braziliensis, the most important etiological agent of the mucocutaneous form of the disease in the New World. Within this context, our group has been working in an attempt to clarify the biological role of these enzymes. In a recent study, we were able to identify the cellular localization of CPs and their mechanism of anchoring to the parasite plasma membrane [84]. The organization of the $c p b$ genes was also determined for this parasite species, along with the subsites of specificity for the recombinant CPB [85].

Most studies about CPB's activity as an immunomodulator were based on the murine model using species from the L. (L.) mexicana complex; however, an in vitro study using cells cultured from dogs and human patients proved that a recombinant $\mathrm{CPB}$ from $L$. (L.) chagasi (rLdccys1) is able to induce cytokine production even in these distinct models. It was shown that rLdccys1 can induce IFN- $\gamma$ production in cell cultures from asymptomatic patients, IFN- $\gamma$, IL- 4 and IL-10 in oligosymptomatic patients and IL-4 and IL-10 (at lower levels) in symptomatic patients and dogs [48].

\section{Immunological effects of the $\mathrm{COOH}$-terminal extension of CPB}

In addition to the aforementioned influence of the proteolytic activity of $\mathrm{CPB}$ on the host immune system, the $\mathrm{COOH}$-terminal extension (CTE) of $\mathrm{CPB}$ has also been reported to influence the interaction of parasites with the host immune system. The CTE is hydrolyzed when $\mathrm{CPB}$ is processed to its mature form [86] and is secreted into the extracellular environment [78]. Because the CTE has also been observed inside host cells [65], this polypeptide may interact with and alter the host immune system.

A synthetic peptide based on the CTE of L. (L.) amazonensis (PI) was shown to induce the expression of Th2-related cytokines in cells cultured from BALB/c mice, whereas cells from CBA mice exposed to the same peptide expressed cytokines related to both Th1 and Th2 responses. $\mathrm{T}$ cell proliferation was also stimulated by the synthetic peptide, especially that of CD8+ T cells. Additionally, when used for in vivo assays with infected mice, PI caused increased growth of lesions for BALB/c mice but not for CBA mice [44]. Our group recently conducted a study using in silico simulations of the interactions between MHC and CTE-derived epitopes, and the results suggested that these interactions could be related to the production of specific cytokines [45].

The CTE may also play a role in macrophage infections with $L$ (L.) pifanoi or $L$. (L.) amazonensis, as incubation of parasites with anti-CTE antibodies prior to their interaction with macrophages led to a reduction in the number of infected cells. This effect was more dramatic with amastigotes than with promastigotes, and pre-incubation of the parasites with an antibody specific to the L. (L.) pifanoi CPB catalytic domain had no effect in macrophage infection [47].

\section{Non-CPB cysteine proteinases}

Regarding the importance of other non-CPB CPs, studies indicate that $\mathrm{CPC}$ also plays a relevant role as a Leishmania virulence factor; although amastigotes from a $\Delta c p c$ L. (L.) mexicana strain were still able to infect macrophages in vitro at rates comparable to the wildtype strain [49], these mutant parasites were more susceptible to killing by host cells [50,51]. Additionally, there is evidence that CPC may contribute to some of the immunoregulatory activities of $L$. (L.) chagasi, such as the parasite's capacity to induce TGF- $\beta$ expression in human cell cultures [52].

Regarding CPA, assays based on gene suppression showed that a CPA (cys1) from L. (L.) infantum acts as a 
virulence factor, as a $\Delta$ Licpa strain of this parasite was less infective for mammalian hosts and for cells in vitro [33].

The synergy between the activities of the CPs that contribute to $L$. (L.) mexicana virulence was verified in assays using parasites that had a combination of $\mathrm{CP}$ genes suppressed $(\Delta c p a / \Delta c p b)$. These mutants were even less infective in BALB/c mice than other strains with just one type of $\mathrm{CP}$ gene suppressed, indicating the complementary activity of these enzymes [34]. A reduction in the virulence of $L$. (L.) mexicana after CP gene suppression was also observed in infection assays in hamsters and in a human mononuclear phagocytic system [87].

An interesting biological function related to the CPA gene has been described. Double $=\Delta c p a / c p b$ mutants of L. (L.) mexicana have a disrupted autophagy pathway and are also unable to undergo metacyclogenesis and transformation to amastigotes [77]. CPA and $\mathrm{CPB}$ are two major lysosomal cysteine peptidases that may function similarly to the aspartic peptidase PEP4 and the serine peptidase PRB1 in Saccharomyces cerevisiae. Autophagy is believed to be necessary to the process of cell differentiation [88].

\section{Endogenous Inhibitors of CPs}

The role of the endogenous CP inhibitors expressed by Leishmania (ICPs) in immune modulation has also been studied. The L. (L.) mexicana mutants that overexpressed the ICPs led to decreased antibody and IL-4 production but induced the production of increased levels of IFN- $\gamma$ in murine hosts when compared to a wild-type strain [46]. These observations reinforce the important role of CPs as immune modulation tools, especially in species of the $L$. $(L$.) mexicana complex.

\section{Metalloproteinases of Leishmania as virulence factors}

The major surface protein (MSP or gp63) is a metalloproteinase (MP) that belongs to the metzincin class (peptidase family M8) and is abundantly expressed on the surface of Leishmania spp. and other related trypanosomatid protozoans [89-92]. Its biological activity is associated with protecting the parasites against the action of host enzymes in the midgut of insect vectors and the phagolysosomes of macrophages. Additionally, gp63 is required for the resistance of promastigotes to complement-mediated lysis in the mammalian host, as the presence of an enzymatically active form of this proteinase greatly reduced the fixation of the terminal complement components on parasites and increased the conversion of C3b to the inactive form C3bi $[53,54]$. The cellular localization of metalloproteinases with domains homologous to gp63 was investigated in $L$. (V.) braziliensis and showed that these enzymes are mainly located in the flagellar pocket of the parasite [93].
Studies of the direct effects of metalloproteinases on the immune system of mammalian hosts show that gp63 is important during macrophage infection and modulates the cytokine immune response, as downregulation of gp63 expression in parasites rendered them more susceptible to complement-mediated lysis and led to the development of a Th1-type response at the site of inoculation and its draining lymph node [55].

Natural killer (NK) cells are another type of immune cell that have been shown to be affected by Leishmania gp63. The ability of promastigotes to suppress this cell type is dependent on gp63 expression, as a $L$. $(L$.) major gp63 mutant strain loses its ability to hinder the proliferation of NK cells and to inhibit the expression of surface receptors on these cells [57].

Gp63 has also been shown to interfere with signaling cascades and to affect transcription factors, thus preventing host cells from adequately responding to the parasites during infection. One example of such activity is the gp63-dependent cleavage of c-Jun, the central component of the transcriptional complex AP-1, by $L$. (L.) mexicana parasites. Interestingly, gp63 retrieved from culture supernatants maintains the capacity to cleave c-Jun, suggesting that when secreted by the parasites, this enzyme may use a phagocytosis-independent mechanism to enter host cells [59].

An alternative immune modulation effect of gp63 occurs by the activation of protein tyrosine phosphatases (PTPs) in macrophages, leading to decreased NO production and attenuated innate inflammatory responses, therefore increasing the parasite's odds of survival. It was reported that gp63 activates at least three macrophage PTPs through its proteolytic activity and that this process is partially dependent on a lipid raft-based mechanism [94].

Similar to CPB, g63 has also been implicated in the cleavage of NF- $\mathrm{kB}$, but this activity has a more subtle and specific purpose than simply preventing the transcriptional factor from reaching the nucleus. Instead, gp63 cleaves the NF-kB subunit p65 into a smaller subunit (p35) that enters the nucleus of the host cell and triggers the expression of chemokines. By subverting the proper function of the transcriptional machinery, the parasites are able to recruit phagocytic cells to serve as hosts while preventing the expression of host factors as IL-12 and iNOS that threaten their survival, [56]. The gp63 from $L$. (L.) major and $L$. (L.) donovani can also cleave CD4 glycoprotein on human T cells in culture, revealing yet another example of the influence that Leishmania parasites have on the host immune system. The cleavage was measured by assessing the binding of specific antibodies binding CD4 glycoprotein on the surface of cells, and this effect was detected using both promastigotes and purified gp63 on the cell cultures [58]. 


\section{Serine-proteinases of Leishmania as virulence factors}

Serine proteinases (SPs) have also been shown to act as virulence factors and influence host immune responses during Leishmania infection, but, unlike CPB for cysteine-proteinases and gp63 for metalloproteinases, there is not yet a specific SP that has been shown to be responsible for these effects. Reports indicate that the levels of surface SPs diminishes in attenuated strains of $L$ (L.) donovani and that a $115 \mathrm{kDa}$ SP seems to be related to the parasite's ability to infect the host [95].

A SP of Leishmania, oligopeptidase B (OPB; Clan SC, family S9A oligopeptidase B), was identified and characterized by mass spectrometry and gene deletion [60]. It was suggested that during differentiation to the amastigote form, OPB is upregulated and participates in the covering of parasite surface with enolase and plasminogen. The amastigotes are then able to replicate undetected within the macrophage.

The direct effects of OPB on the host immune system was demonstrated by examining the effect of infection with an OPB mutant strain on the expression of host genes. Infection of macrophages in culture with a wildtype $L$. $(L$.) donovani strain results in changes in the expression of 23 genes, but infection of these same cells with a mutant strain in which the oligopeptidase $B$ gene was deleted leads to changes in 495 genes, an increase of approximately $21 \mathrm{x}$ in the number of genes affected by the infection. This suggests a relationship between oligopeptidase $\mathrm{B}$ expression and the ability of Leishmania to remain undetected in macrophage infections [60]. OPBdeficient $L$. (L.) major mutants were recently shown to be able to grow normally as promastigotes even though they are slightly deficient in their ability to undergo differentiation to metacyclic promastigotes, but they were significantly less able to infect and survive within macrophages in vitro despite maintaining their virulence in mice. These data suggest that $L$. (L.) major OPB itself is not a prevalent virulence factor but rather acts in conjunction with other factors, indicating functional differences between trypanosomes and Leishmania in their interaction with the mammalian host [96].

Another class of SP, the subtilisin protease (SUB; Clan $\mathrm{SB}$, family S8) of $L$. (L.) donovani, was cloned and shown to possess a unique catalytic triad. When this SP gene was deleted, the ability of the parasite to undergo promastigote to amastigote differentiation in vitro was reduced. Furthermore, the activity of this Leishmania SP is increased by several fold in amastigotes when compared to promastigotes, suggesting an important role for this enzyme in the vertebrate-inhabiting stages of the parasite [61].

Additional evidence of immune modulation by SPs was obtained by the observation that immunization with a soluble proteases fraction isolated from a mixture of $L$.
(L.) amazonensis antigens increased the susceptibility of mice to a subsequent experimental infection. This effect was eliminated by treating the protease fraction with SP inhibitors but not with CP inhibitors [62].

\section{Importance of proteinases from mammalian host in the progression of the infection}

Although the proteinases from parasites play important roles in immunomodulating the host response and, consequently, the outcome of the infection, proteinases from the host also affect the dynamics of the infection and the development of the lesion. For example, matrix metalloprotease-9 (MMP-9) interferes with the reepithelization of chronic wounds in humans. In situations where the inflammation continues for a long period, TNF- $\alpha$ and, subsequently, MMP-9 persist, thereby preventing the migrating keratinocytes from forming new attachments to a newly synthesized basement membrane. This suggests a mechanism whereby the presence of high levels of MMP-9 delays the process of normal wound healing [97].

These data are correlated with findings that associate a high number of cells producing IFN- $\gamma$, IL-10 and TNF$\alpha$, in addition to elevated levels of MMP- 9 activity in lesions, with a poor response to therapeutics for cutaneous leishmaniasis (CL) [98]. Indeed, infection with $L$. (L.) chagasi stimulates murine macrophages to produce MMP-9 [99]. Conversely, elevated levels of MMP-2 mRNA were detected in lesions from patients with good responses to treatment [98], an observation consistent with other reports that showed that increased MMP-2 levels were required for cutaneous wound reepithelization [100]. Interleukin-10 is observed at higher levels in patients with good immune responses [98] and seems to be unique among the cytokines in its ability to suppress the production and activation of MMPs, thus having an important matrix-protective role during inflammation [101].

\section{Remarks}

The network of interactions that take place during the evolution of the Leishmania infection in the mammal host is highly complex and involves a series of responses and counter-responses from both organisms. In this context, proteinases appear as factors of pivotal importance, playing central roles in many of the interactions between parasite and host (Table 1).

Although most of the literature currently available on this subject is focused on cysteine-, metallo- and serineproteinases from Leishmania species, the importance of host proteinases, such as matrix metalloproteinases, and their role in the subversion of host's immune responses by the parasites must not be overlooked, as some reports already point to their direct contribution to determining 
the outcome of infections. Furthermore, it is necessary to analyze the participation of aspartyl-proteinases from Leishmania species, as their expression changes between morphological forms and may therefore be related to the responses necessary to survive in distinct microenvironments [65]. Therefore, to fully understand how the Leishmania infection progresses and to be able to find suitable targets for drug development and options for patient treatment, it is important to consider the influence of proteinases from host and parasite alike, as disregarding one in favor of the other may lead to incorrect conclusions and inadequate, if not harmful, treatment of the disease.

\section{Competing interests}

The authors declare that they have no competing interests.

\section{Authors' contributions}

CRA formulated the idea and CRA, MSA, BASP and MLRG wrote the manuscript. All authors approved the final version of this manuscript.

\section{Acknowledgements}

This study received financial support from PAPES (CNPq/Fiocruz) and FAPERJ. MSc Mariana Silva-Almeida is doctoral study fellow of the Fiocruz/CAPES institution. Dr. Bernardo Acácio Santini Pereira and Dr. Michelle Lopes Ribeiro-Guimarães are postdoctoral fellow researchers of CAPES/FAPERJ and CAPES, respectively. Dr. Carlos Roberto Alves is a fellow researcher from CNPq.

Received: 1 March 2012 Accepted: 12 July 2012

Published: 7 August 2012

\section{References}

1. Allison MJ: Leishmaniasis. In The Cambridge World History of Human Disease. Edited by Kiple KF. Cambridge Histories Online: Cambridge University Press; 1993. doi:10.1017/CHOL9780521332866.141. Vol 1.

2. Stark D, van Hal S, Lee R, Marriott D, Harkness J: Leishmaniasis, an emerging imported infection: report of 20 cases from Australia. J Travel Med 2008, 15(5):351-354.

3. Gramiccia M, Gradoni L: The current status of zoonotic leishmaniases and approaches to disease control. Int J Parasitol 2005, 35:1169-1180.

4. Desjeux P: Leishmaniasis: current situation and new perspectives. Comp Immunol Microbiol Infect Dis 2004, 27(5):305-318.

5. Pavlia A, Maltezoub HC: Leishmaniasis, an emerging infection in travelers. Inter J Infect Dis 2010, 14(12):e1032-e1039.

6. Bates PA, Rogers ME: New insights into the developmental biology and transmission mechanisms of Leishmania. Curr Mol Med 2004, 4(6):601-609.

7. Marzochi MC, Marzochi KB: Tegumentary and visceral leishmaniases in Brazil: emerging anthropozoonosis and possibilities for their control. Cad Saude Publica 1994, 10(suppl 2):359-375.

8. Reithinger R, Dujardin JC, Louzir H, Pirmez C, Alexander B, Brooker S: Cutaneous Leishmaniasis. Lancet Infect Dis 2007, 7(9):581-596.

9. McGwire BS, Chang KP, Engman DM: Migration through the extracellular matrix by the parasitic protozoan Leishmania is enhanced by surface metalloprotease gp63. Infect Immun 2003, 71(2):1008-1010.

10. Lira R, Rosales-Encina JL, Argüello C: Leishmania mexicana: binding of promastigotes to type I collagen. Exp Parasitol 1997, 85(2):149-157.

11. Castes M, Agnellia A, Verde O, Rondón AJ: Characterization of the cellular immune response in American cutaneous leishmaniasis. Clin Immunol Immunopathol 1983, 27(2):176-186.

12. Pirmez C: Immunopathology of American cutaneous leishmaniasis. Mem Inst Oswaldo Cruz 1992, 87(suppl 5):105-109.

13. Lessa MM, Lessa HA, Castro TW, Oliveira A, Scherifer A, Machado P, Carvalho EM: Mucosal leishmaniasis: epidemiological and clinical aspects. Braz J Otorhinolaryngol 2007, 73(6):843-847.
14. Sinha S, Fernández G, Kapila R, Lambert WC, Schwartz RA: Diffuse cutaneous leishmaniasis associated with the immune reconstitution inflammatory syndrome. Int J Dermato/ 2008, 47(12):1263-1270.

15. Matlashewski G: Leishmania infection and virulence. Med Microbiol Immunol 2001, 190:37-42.

16. Proudfoot L, O'Donnell CA, Liew FY: Glycoinositolphospholipids of Leishmania major inhibit nitric oxide synthesis and reduce leishmanicidal activity in murine macrophages. Eur J Immunol 1995, 25(3):745-750.

17. Zufferey R, Allen S, Barron T, Sullivan DR, Denny PW, Almeida IC, Smith DF, Turco SJ, Ferguson MA, Beverley SM: Ether phospholipids and glycosylinositolphospholipids are not required for amastigote virulence or for inhibition of macrophage activation by Leishmania major. J Biol Chem 2003, 278(45):44708-44718.

18. Yoneyama KA, Tanaka AK, Silveira TG, Takahashi HK, Straus AH: Characterization of Leishmania (Viannia) braziliensis membrane microdomains, and their role in macrophage infectivity. J Lipid Res 2006, 47(10):2171-2178.

19. Svárovská A, Ant TH, Seblová V, Jecná L, Beverley SM, Volf P: Leishmania major glycosylation mutants require phosphoglycans (lpg2-) but not lipophosphoglycan (lpg1-) for survival in permissive sand fly vectors. PLoS Negl Trop Dis. 2010, 4(1):e580.

20. Gaur U, Showalter M, Hickerson S, Dalvi R, Turco SJ, Wilson ME, Beverley SM: Leishmania donovani lacking the Golgi GDP-Man transporter LPG2 exhibit attenuated virulence in mammalian hosts. Exp Parasitol. 2009, 122(3):182-91.

21. Handman E, Goding JW: The Leishmania receptor for macrophages is a lipid-containing glycoconjugate. EMBO J 1985, 4(2):329-336.

22. Späth GF, Epstein L, Leader B, Singer SM, Avila HA, Turco SJ, Beverley SM: Lipophosphoglycan is a virulence factor distinct from related glycoconjugates in the protozoan parasite Leishmania major. Proc Natl Acad Sci USA 2000, 97(16):9258-9263.

23. Späth GF, Garraway LA, Turco SJ, Beverley SM: The role(s) of lipophosphoglycan (LPG) in the establishment of Leishmania major infections in mammalian hosts. Proc Natl Acad Sci USA 2003, 100(16):9536-9541.

24. Argueta-Donohué J, Carrillo N, Valdés-Reyes L, Zentella A, Aguirre-García M, Becker I, Gutiérrez-Kobeh L: Leishmania mexicana: participation of NFkappaB in the differential production of IL-12 in dendritic cells and monocytes induced by lipophosphoglycan (LPG). Exp Parasitol 2008, 120(1):1-9.

25. Liu D, Kebaier C, Pakpour N, Capul AA, Beverley SM, Scott P, Uzonna JE: Leishmania major phosphoglycans influence the host early immune response by modulating dendritic cell functions. Infect Immun 2009, 77(8):3272-3283.

26. $\lg \mathrm{T}$, Montgomery J, Stierhof YD, Handman E: Molecular cloning and characterization of a novel repeat-containing Leishmania major gene pp g1, that encodes a membrane-associated form of proteophosphoglycan with a putative glycosylphosphatidylinositol anchor. J Biol Chem 1999, 274(44):31410-31420.

27. Ilg T: Proteophosphoglycans of Leishmania. Parasitol Today 2000, 16(11):489-497.

28. Peters C, Stierhof YD, Ilg T: Proteophosphoglycan secreted by Leishmania mexicana amastigotes causes vacuole formation in macrophages. Infect Immun 1997, 65(2):783-786.

29. Peters C, Kawakami M, Kaul M, Ilg T, Overath P, Aebischer T: Secreted proteophosphoglycan of Leishmania mexicana amastigotes activates complement by triggering the mannan binding lectin pathway. Eur $\mathrm{J}$ Immunol 1997, 27(10):2666-2672.

30. Jardim A, Funk V, Caprioli RM, Olafson RW: Isolation and structural characterization of the Leishmania donovani kinetoplastid membrane protein-11, a major immunoreactive membrane glycoprotein. Biochem J 1995, 305:307-313.

31. Carvalho LP, Passos S, Dutra WO, Soto M, Alonso C, Gollob KJ, Carvalho EM Ribeiro de Jesus A: Effect of LACK and KMP11 on IFN-gamma production by peripheral blood mononuclear cells from cutaneous and mucosal leishmaniasis patients. Scand J Immunol 2005, 61(4):337-342.

32. Barrett AJ: Classification of peptidases. Methods Enzymol 1994, 244:1-15.

33. Denise H, Poot J, Jiménez M, Ambit A, Herrmann DC, Vermeulen AN, Coombs GH, Mottram JC: Studies on the CPA cysteine peptidase in the Leishmania infantum genome strain JPCM5. BMC Mol Biol 2006, 13(7):42. 
34. Mottram JC, Coombs GH, Alexander J: Cysteine peptidases as virulence factors of Leishmania. Curr Opin Microbiol 2004, 7(4):375-381.

35. Alexander J, Coombs GH, Mottram JC: Leishmania mexicana cysteine proteinase-deficient mutants have attenuated virulence for mice and potentiate a Th1 response. J Immunol 1998, 161(12):6794-6801.

36. Denise H, McNeil K, Brooks DR, Alexander J, Coombs GH, Mottram JC: Expression of multiple CPB genes encoding cysteine proteases is required for Leishmania mexicana virulence in vivo. Infect Immun 2003, 71(6):3190-3195.

37. Buxbaum LU, Denise H, Coombs GH, Alexander J, Mottram JC, Scott P: Cysteine protease B of Leishmania mexicana inhibits host Th1 responses and protective immunity. J Immunol 2003, 171(7):3711-3717.

38. Weinheber N, Wolfram M, Harbecke D, Aebischer T: Phagocytosis of Leishmania mexicana amastigotes by macrophages leads to a sustained suppression of IL-12 production. Eur J Immunol 1998, 28(8):2467-2477

39. Bennett CL, Misslitz A, Colledge L, Aebischer T, Blackburn CC: Silent infection of bone marrow-derived dendritic cells by Leishmania mexicana amastigotes. Eur J Immunol 2001, 31(3):876-883.

40. Cameron P, McGachy A, Anderson M, Paul A, Coombs GH, Mottram JC Alexander J, Plevin R: Inhibition of lipopolysaccharide-induced macrophage IL-12 production by Leishmania mexicana amastigotes: the role of cysteine peptidases and the NF-kappaB signaling pathway. $\mathrm{J}$ Immunol 2004, 173(5):3297-3304.

41. Abu-Dayyeh I, Hassani K, Westra ER, Mottram JC, Olivier M: Comparative study of the ability of Leishmania mexicana promastigotes and amastigotes to alter macrophage signaling and functions. Infect Immun 2010, 78(6):2438-2445.

42. Pollock KG, McNeil KS, Mottram JC, Lyons RE, Brewer JM, Scott P, Coombs $\mathrm{GH}$, Alexander J: The Leishmania mexicana cysteine protease, CPB2.8, induces potent Th2 responses. J Immunol 2003, 170(4):1746-1753.

43. De Souza Leao S, Lang T, Prina E, Hellio R, Antoine JC: Intracellular Leishmania amazonensis amastigotes internalize and degrade MHC class II molecules of their host cells. J Cell Sci 1995, 108:3219-3231.

44. Alves CR, Benévolo-De-Andrade TC, Alves JL, Pirmez C: Th1 and Th2 immunological profile induced by cysteine proteinase in murine leishmaniasis. Parasite Immunol 2004, 26(3):127-135.

45. Pereira BA, Silva FS, Rebello KM, Marín-Villa M, Traub-Cseko YM, Andrade TC, Bertho ÁL, Caffarena ER, Alves CR: In silico predicted epitopes from the $\mathrm{COOH}$-terminal extension of cysteine proteinase $\mathrm{B}$ inducing distinct immune responses during Leishmania (Leishmania) amazonensis experimental murine infection. BMC Immunol 2011, 12:44.

46. Bryson K, Besteiro S, McGachy HA, Coombs GH, Mottram JC, Alexander J: Overexpression of the natural inhibitor of cysteine peptidases in Leishmania mexicana leads to reduced virulence and a Th1 response. Infect Immun 2009, 77(7):2971-2978.

47. Marín-Villa M, Vargas-Inchaustegui DA, Chaves SP, Tempone AJ, Dutra JM, Soares MJ, Ueda-Nakamura T, Mendonça SC, Rossi-Bergmann B, Soong L, Traub-Csekö YM: The C-terminal extension of Leishmania pifanoi amastigote-specific cysteine proteinase Lpcys2: a putative function in macrophage infection. Mol Biochem Parasitol 2008, 162(1):52-59.

48. da Costa Pinheiro PH, de Souza Dias S, Eulálio KD, Mendonça IL, Katz S, Barbiéri CL: Recombinant cysteine proteinase from Leishmania (Leishmania) chagasi implicated in human and dog T-cell responses. Infect Immun 2005, 73(6):3787-3789.

49. Frame MJ, Mottram JC, Coombs GH: Analysis of the roles of cysteine proteinases of Leishmania mexicana in the host-parasite interaction. Parasitology 2000, 121:367-377.

50. Bart G, Frame MJ, Carter R, Coombs GH, Mottram JC: Cathepsin B-like cysteine proteinase-deficient mutants of Leishmania mexicana. Mol Biochem Parasitol 1997, 88(1-2):53-61.

51. Mottram JC, Brooks DR, Coombs GH: Roles of cysteine proteinases of trypanosomes and Leishmania in host-parasite interactions. Curr Opin Microbiol 1998, 1(4):455-460.

52. Somanna A, Mundodi V, Gedamu L: Functional analysis of cathepsin B-like cysteine proteases from Leishmania donovani complex. Evidence for the activation of latent transforming growth factor beta. J Biol Chem 2002, 277(28):25305-25312.

53. Yao C, Donelson JE, Wilson ME: The major surface protease (MSP or GP63) of Leishmania sp. Biosynthesis, regulation of expression, and function. Mol Biochem Parasitol 2003, 132(1):1-16.
54. Yao C: Major Surface Protease of Trypanosomatids: One Size Fits All? Infect Immun 2010, 78(1):22-31.

55. Thiakaki M, Kolli B, Chang KP, Soteriadou K: Down-regulation of gp63 level in Leishmania amazonensis promastigotes reduces their infectivity in BALB/c mice. Microbes Infect 2006, 8(6):1455-1463.

56. Gregory DJ, Godbout M, Contreras I, Forget G, Olivier M: A novel form of NF-kappaB is induced by Leishmania infection: involvement in macrophage gene expression. Eur J Immunol 2008, 38(4):1071-1081.

57. Lieke T, Nylén S, Eidsmo L, McMaster WR, Mohammadi AM, Khamesipour A, Berg L, Akuffo H: Leishmania surface protein gp63 binds directly to human natural killer cells and inhibits proliferation. Clin Exp Immunol 2008, 153(2):221-230.

58. Hey AS, Theander TG, Hviid L, Hazrati SM, Kemp M, Kharazmi A: The major surface glycoprotein (gp63) from Leishmania major and Leishmania donovani cleaves CD4 molecules on human T cells. J Immunol 1994, 152(9):4542-4548.

59. Contreras I, Gómez MA, Nguyen O, Shio MT, McMaster RW, Olivier M: Leishmania-induced inactivation of the macrophage transcription factor AP-1 is mediated by the parasite metalloprotease GP63. PLOS Pathog 2010, 6(1):e1001148.

60. Swenerton RK, Zhang S, Sajid M, Medzihradszky KF, Craik CS, Kelly BL, McKerrow JH: The oligopeptidase B of Leishmania regulates parasite enolase and immune evasion. J Biol Chem 2011, 286(1):429-440.

61. Swenerton RK, Knudsen GM, Sajid M, Kelly BL, McKerrow JH: Leishmania subtilisin is a maturase for the trypanothione reductase system and contributes to disease pathology. J Biol Chem 2010, 285(41): 31120-31129.

62. Pinheiro RO, Pinto EF, Lopes JR, Guedes HL, Fentanes RF, Rossi-Bergmann B: TGF-beta-associated enhanced susceptibility to leishmaniasis following intramuscular vaccination of mice with Leishmania amazonensis antigens. Microbes Infect 2005, 7(13):1317-1323.

63. Rawlings ND, Barrett AJ, Bateman A: MEROPS: the peptidase database. Nucleic Acids Res 2010, 38:D227-D233.

64. Silva-Lopez RE, Morgado-Díaz JA, Alves CR, Côrte-Real S, Giovanni-DeSimone S: Subcellular localization of an extracellular serine protease in Leishmania (Leishmania) amazonensis. Parasitol Res 2004, 93(4):328-331.

65. Alves CR, Corte-Real S, Bourguignon SC, Chaves CS, Saraiva EM: Leishmania amazonensis: early proteinase activities during promastigote-amastigote differentiation in vitro. Exp Parasitol 2005, 109(1):38-48.

66. Valdivieso E, Dagger F, Rascón A: Leishmania mexicana: identification and characterization of an aspartyl proteinase activity. Exp Parasitol 2007, 116(1):77-82.

67. Sajid M, McKerrow JH: Cysteine proteases of parasitic organisms. Mol Biochem Parasitol 2002, 120(1):1-21.

68. McKerrow JH, Caffrey C, Kelly B, Loke P, Sajid M: Proteases in parasitic diseases. Ann Rev Pathol 2006, 1:497-536.

69. Selzer PM, Pingel S, Hsieh I, Ugele B, Chan VJ, Engel JC, Bogyo M, Russell DG, Sakanari JA, McKerrow JH: Cysteine protease inhibitors as chemotherapy: lessons from a parasite targe. Proc Natl Acad Sci USA 1999, 96(20):11015-11022.

70. Vermelho AB, Branquinha MH, D'Ávila-Levy CM, Santos ALS, Dias EPS, Melo ACN: Biological Roles of Peptidases in Trypanosomatids. Open Parasitol J 2010, 4:5-23.

71. Sakanari JA, Nadler SA, Chan VJ, Engel JC, Leptak C, Bouvier J: Leishmania major: comparison of the cathepsin L- and B-like cysteine protease genes with those of other trypanosomatids. Exp Parasitol 1997, 85(1):63-76.

72. Robertson CD, Coombs GH: "Cathepsin B-like cysteine proteases of Leishmania mexicana. Mol Biochem Parasitol 1993, 62(2):271-279.

73. Robertson $\mathrm{CD}$, Coombs GH: Multiple high activity cysteine proteases of Leishmania mexicana are encoded by the Imcpb gene array. Microbiology 1994, 140(2):417-424.

74. Souza AE, Waugh S, Coombs GH, Mottram JC: Characterization of a multicopy gene for a major stage-specific cysteine proteinase of Leishmania mexicana. FEBS Lett 1992, 311(2):124-127.

75. Mottram JC, Frame MJ, Brooks DR, Tetley L, Hutchison JE, Souza AE, Coombs GH: The multiple cpb cysteine proteinase genes of Leishmania mexicana encode isoenzymes that differ in their stage regulation and substrate preferences. J Biol Chem 1997, 272(22):14285-14293.

76. Traub-Cseko YM, Duboise M, Boukai LK, McMahon-Pratt D: Identification of two distinct cysteine proteinase genes of Leishmania pifanoi axenic 
amastigotes using the polymerase chain reaction. Mol Biochem Parasitol 1993, 57(1):101-115.

77. Lasakosvitsch F, Gentil LG, dos Santos MR, da Silveira JF, Barbiéri CL: Cloning and characterization of a cysteine proteinase gene expressed in amastigotes of Leishmania (L.) amazonensis. Int J Parasitol 2003, 33(4):445-454

78. Mundodi V, Somanna A, Farrell PJ, Gedamu L: Genomic organization and functional expression of differentially regulated cysteine protease genes of Leishmania donovani complex. Gene 2002, 282(1-2):257-265.

79. Hide M, Bañuls AL: Polymorphisms of cpb multicopy genes in the Leishmania (Leishmania) donovani complex. Trans R Soc Trop Med Hyg 2008, 102(2):105-106.

80. de Araújo Soares RM, dos Santos AL, Bonaldo MC, de Andrade AF, Alviano CS, Angluster J, Goldenberg S: Leishmania (Leishmania) amazonensis: differential expression of proteinases and cell-surface polypeptides in avirulent and virulent promastigotes. Exp Parasitol 2003, 104(3-4):104-112.

81. Poot J, Denise H, Herrmann DC, Mottram JC, Coombs GH, Vermeulen AN: Virulence and protective potential of several Cysteine peptidase knockout strains of Leishmania infantum in hamsters. In Experimental challenge models for canine leishmaniasis in hamsters and dogs, optimization and application in vaccine research. Edited by Poot J. Utrecht, Netherlands: Utrecht University press; 2006:93-107.

82. Mundodi V, Kucknoor AS, Gedamu L: Role of Leishmania (Leishmania) chagasi amastigote cysteine protease in intracellular parasite survival: studies by gene disruption and antisense mRNA inhibition. BMC Mol Biol 2005, 6(1):3

83. Mahmoudzadeh-Niknam H, McKerrow JH: Leishmania tropica: cysteine proteases are essential for growth and pathogenicity. Exp Parasitol 2004 106(3-4):158-163

84. Rebello KM, Côrtes LM, Pereira BA, Pascarelli BM, Côrte-Real S, Finkelstein LC, Pinho RT, d'Avila-Levy CM, Alves CR: Cysteine proteinases from promastigotes of Leishmania (Viannia) braziliensis. Parasitol Res 2009, 106(1):95-104.

85. Lanfranco MF, Loayza-Muro R, Clark D, Núñez R, Zavaleta Al, Jimenez M, Meldal M, Coombs GH, Mottram JC, Izidoro M, Juliano MA, Juliano L, Arévalo J: Expression and substrate specificity of a recombinant cysteine proteinase B of Leishmania braziliensis. Mol Biochem Parasitol 2008, 161(2):91-100.

86. Duboise SM, Vannier-Santos MA, Costa-Pinto D, Rivas L, Pan AA, TraubCseko Y, De Souza W, McMahon-Pratt D: The biosynthesis, processing, and immunolocalization of Leishmania pifanoi amastigote cysteine proteinases. Mol Biochem Parasitol 1994, 68(1):119-132.

87. Saravia NG, Escorcia B, Osorio Y, Valderrama L, Brooks D, Arteaga L, Coombs G, Mottram J, Travi BL: Pathogenicity and protective immunogenicity of cysteine proteinase-deficient mutants of Leishmania mexicana in nonmurine models. Vaccine 2006, 24(19):4247-4259.

88. Williams RA, Tetley L, Mottram JC, Coombs GH: Cysteine peptidases CPA and CPB are vital for autophagy and differentiation in Leishmania mexicana. Mol Microbiol 2006, 61(3):655-674

89. Bouvier J, Etges RJ, Bordier C: Identification and purification of membrane and soluble forms of the major surface protein of Leishmania promastigotes. J Biol Chem 1985, 260(29):15504-15509.

90. Etges RJ, Bouvier J, Hoffman R, Bordier C: Evidence that the major surface proteins of three Leishmania species are structurally related. Mol Biochem Parasitol 1985, 14(2):141-149.

91. Etges R, Bouvier J, Bordier C: The major surface protein of Leishmania promastigotes is a protease. J Biol Chem 1986, 261(20):9098-9101.

92. Schlagenhauf E, Etges R, Metcalf P: The crystal structure of the Leishmania major surface proteinase leishmanolysin (gp63). Structure 1998, 6(8):1035-1046.

93. Cuervo P, Santos AL, Alves CR, Menezes GC, Silva BA, Britto C, Fernandes O, Cupolillo E, Batista De Jesus J: Cellular localization and expression of gp63 homologous metalloproteases in Leishmania (Viannia) braziliensis strains. Acta Trop 2008, 106(3):143-148.

94. Gomez MA, Contreras I, Hallé M, Tremblay ML, McMaster RW, Olivier M: Leishmania GP63 alters host signaling through cleavage-activated protein tyrosine phosphatases. Sci Signal 2009, 2(90):ra58.

95. Choudhury R, Das P, Bhaumik SK, De T, Chakraborti T: In situ immunolocalization and stage-dependent expression of a secretory serine protease in Leishmania donovani and its role as a vaccine candidate. Clin Vaccine Immunol 2010, 17(4):660-667.
96. Munday JC, McLuskey K, Brown E, Coombs GH, Mottram JC: Oligopeptidase B deficient mutants of Leishmania major. Mol Biochem Parasitol 2011, 175(1):49-57.

97. Reiss MJ, Han YP, Garcia E, Goldberg M, Yu H, Garner WL: Matrix metalloproteinase- 9 delays wound healing in a murine wound model. Surgery 2010, 147(2):295-302

98. Maretti-Mira AC, de Oliveira-Neto MP, Da-Cruz AM, de Oliveira MP, Craft N Pirmez C: Therapeutic failure in American cutaneous leishmaniasis is associated with gelatinase activity and cytokine expression. Clin Exp Immunol 2011, 163(2):207-214.

99. Costa JD, de Melo AC N, Vermelho AB, Meirelles Mde N, Porrozzi R: In vitro evidence for metallopeptidase participation in hepatocyte damage induced by Leishmania chagasi-infected macrophages. Acta Trop 2008 106(3):175-183.

100. Agren MS, Mirastschijski U, Karlsmark T, Saarialho-Kere UK: Topical synthetic inhibitor of matrix metalloproteinases delays epidermal regeneration of human wounds. Exp Dermatol 2001, 10(5):337-348.

101. Stearns ME, Wang M, Hu Y, Garcia FU, Rhim J: Interleukin 10 blocks matrix metalloproteinase-2 and membrane type 1-matrix metalloproteinase synthesis in primary human prostate tumor lines. Clin Cancer Res 2003 9(3):1191-1199.

\section{doi:10.1186/1756-3305-5-160}

Cite this article as: Silva-Almeida et al:: Proteinases as virulence factors in Leishmania spp. infection in mammals. Parasites \& Vectors 2012 5:160.

\section{Submit your next manuscript to BioMed Central and take full advantage of:}

- Convenient online submission

- Thorough peer review

- No space constraints or color figure charges

- Immediate publication on acceptance

- Inclusion in PubMed, CAS, Scopus and Google Scholar

- Research which is freely available for redistribution 